\title{
Being Itself, Limit Situation, Temporality and Existence as an Analytical Structure for Existencial Enlightenment
}

\author{
Hugo Campos-Winter \\ Escuela de Graduados, Facultad de Filosofía y Humanidades, Universidad Austral de Chile, Valdivia, Chile \\ Email: hugo.campos.w@gmail.com
}

How to cite this paper: Campos-Winter, H. (2020). Being Itself, Limit Situation, Temporality and Existence as an Analytical Structure for Existencial Enlightenment. Open Journal of Philosophy, 10, 113-128. https://doi.org/10.4236/ojpp.2020.101008

Received: January 2, 2020

Accepted: February 8, 2020

Published: February 11, 2020

Copyright $\odot 2020$ by author(s) and Scientific Research Publishing Inc. This work is licensed under the Creative Commons Attribution International License (CC BY 4.0).

http://creativecommons.org/licenses/by/4.0/

\section{(c) (i) Open Access}

\begin{abstract}
Karl Jaspers considers that in order to advent to Being itself, certain limit situations must be faced, among which are death, suffering, struggle, chance and guilt. Only by entering these limit situations does it come into existence. But Jaspers did not consider time as a limit situation in which we are from the origin in an improper time and from which we make the existencial leap to our own time through decisive precursor actions. This article argues that time, considered mainly from Heidegger, is properly a limit situation, which, through its willful confrontation, advents to Being itself. For this reason, a phenomenological hermeneutical investigation is carried out, that semantically updates the concepts of Being itself, the limit situation, temporality and existence.
\end{abstract}

Keywords

Being Itself, Limit Situation, Temporality, Existence

\section{Introduction}

Existential enlightenment in Karl Jaspers psychology and philosophy plays a key role, this process is carried out by understanding the limit situations in which we enter as existing empirical and from which we come out as being itself or existence. The author considered death, struggle, guilt, chance and suffering as limit situations. Each of these limit situations implies as a way out to advent to Being itself, so far as they bring with them certain types of leaps to existence. Indeed, understanding limit situations from the point of view of existence is a fundamental step in being itself, and getting into Being itself is identical to the exercise of freedom as well as/or unconditional actions that are a source of meaning of 
life.

This article proposes to consider time as a limit situation in which we are from the beginning, with an improper time in the present, and gets out of it with our proper time, through decisive precursor actions that project the future, which aims to contribute to existential enlightenment to the extent that it deepens the semantic discourse about getting into Being itself.

First, the concept of Being itself is defined as the result of will, reflection and self-consciousness, then the concepts of situation and limit situation are defined as entics dispositions in which the existing empirical subjectively and objectively finds a limit to it and a possibility of Being itself, thirdly, the concept of temporality is given semantic depth to construct it as a limiting situation. Finally, the concepts of empirical existence, existence (Being itself), the limit situation and time are articulated to argue that the empirical existing can get to Being itself through its jump from improper time and exercise of one's own time, making the leap from intramundane mediocrity to existence.

\section{Theoretical Method}

In phenomenological hermeneutic research, the being must be understood and schematized based on the entity that is the existing empirical. Just as Husserl uses the epoché and the phenomenological reduction to access the essences in consciousness, from Heidegger (2000: p. 47), "The fundamental component of the phenomenological method, in the sense of reconduction of the inquisitive gaze from the entity naively understood to being, we designate it as phenomenological reconduction".

In terms of this article, the foregoing means that the investigation starts from the literal understanding according to the arquitas principle, from the concepts of Being itself, limit situation, temporality and existence, "But later it moves away, in some way, from that entity and turns to the being of that entity" (Heidegger, 2000: p. 47), that is, to its origin in the Dasein or Being itself interpreted from its current historical and daily situation, in which the Dasein is interpreted as situated (Campos, 2017) and projecting (Holzapfel, 2015, 2014). Therefore, the reconduction "Means the reconduction of the phenomenological view from the understanding, always concrete, of an entity to the understanding of the being of that entity (projected on the way of its being unveiled [Unverborgenheit]" (Heidegger, 2000: p. 47) historically, because "Dasein is historical" (Heidegger, 2000: p. 48).

Then, the deviation of the gaze from the concrete entity, present, in sight, towards its being or original display of its way of being historically timed, as a negative moment, is accompanied by a positive methodological moment of conduction, called phenomenological construction. Since "The being is not as accessible as the entity, we are not easily in front of it, but, as will be shown, it must always be brought under the gaze in a free projection [Entwurf]" (Heidegger, 2000: p. 47). This implies the construction of the concept of temporality as a 
limit situation in which it is in the improper time mode, and from which it comes out through the proper time of the resolute precursor actions (Heidegger, 2015: p. 356).

But this free projection of the phenomenological construction meets the obstacle of tradition or the average understanding of being, "Every philosophical exposition (...) is penetrated entirely by traditional concepts, and, therefore, by traditional horizons and perspectives that we cannot affirm, as evident from theirs, they have emerged authentically and originally from the realm of being and from the understanding of being, which they intend to understand" (Heidegger, 2000: p. 48). Indeed, "It necessarily belongs to the conceptual interpretation of being and its structures (...) a destruction, that is, a critical destruction [Abbau] of traditional concepts, which, in the beginning, must necessarily be used" (Heidegger, 2000: p. 48). This step of eliminating barriers to construction is fundamental, so "Only by destruction can the ontology ensure phenomenologically the authenticity of its concepts" (Heidegger, 2000: p. 48). This means that all phenomenological constructions meet its trivial understanding, coined by the conceptual tradition that has addressed it so far. It also implies that this article deconstructs the senses of the concepts used to link them by synonymously, updating it by re-semantization through the study of micro and macro meanings (Wotjak, 1979). This treatment of concepts is based on their participation in the existentialist argumentative tradition, in which strong relationships of conceptual influence are evident, for example, how Holzapfel (2001) teaches, in the case of Jaspers regarding Heidegger.

This is how "The construction of philosophy is necessarily destruction, that is, a deconstruction of the transmitted ones carried out through a return to tradition, which does not mean negation of it, or a prejudice that considers tradition to be nothing, but, on the contrary, a positive appropriation of it" (Heidegger, 2000: p. 49).

In conclusion, "These three fundamental components of the phenomenological method, reduction, construction and destruction, belong to each other and must be grounded in their mutual belonging" (Heidegger, 2000: p. 48).

In this Trinitarian method, thinking from Jaspers (1960), certain research attitudes must be developed. An aesthetic attitude of isolation regarding the concepts in research contemplated as a whole, a rational attitude that reveals the essentials of the concepts, an intuitive attitude that allows itself to be carried out and projects the temporality of the concept, an active attitude that deconstructs the tradition and builds senses of the concepts, and an enthusiastic attitude where both, research subject and concepts are considered as subjects. With these attitudes the man can "build upon the world of his perception, an ideal realm of thought" (Scheller, 1938: p. 72).

According to Jaspers, "phenomenology is an empirical method for investigating individual psychic experience (p. 55)" (McMillan, 2002: p. 91). In effect, that is the aim of this article. This is, to make the phenomenon of being itself intui- 
tive, and "although what is mentioned is not at all perceivable by the senses, which can be seen with the eye or heard with the ear, however it in what it is can be captured and held for understanding" (Heidegger, 2004: p. 89). In other words, the aim of the method is to produce an insight cultivating writing (Van Manen, 2014).

\section{Existential Analysis}

\subsection{Being Itself}

In the concept of being itself, there are the noema it, which means the positivity of being there, the noema self, which means that such being there is our own being, and the noema Being which refers that we are not the foundation of our being there, but we are responsible, and with which we have to see each other every moment. In fact, according to Jaspers, the fundamental thing about the Being itself is that "Something behaves towards itself" (Jaspers, 1960: p. 541), that is to say, the self that reflects its being there is becoming reflective of it by actively objectifying its being there, in such a way that "The self becomes conscious of Being itself by intentionally addressing its empirical existence, as one that at the same time is two, which, even differing, remain, however, one (...), as the one in the present moment and as the one through the succession of time remembered or thought of as future" (Jaspers, 1958a: pp. 422-423). This implies that neither it alone nor the self through intellectual actions of the world are each one for their own Being itself, not even the self that merely reflects their empirical existence, but that the Being itself is the self-conscious relationship between the self and it, as if self and it there formed a symmetrical relationship in relation to a general Being that contains them as a unitary set. Therefore, the self-conscious factor is the fundamental issue in the self for its existence.

Also, as a conjunction of form and matter, the Being itself is a synthesis of existential opponents structurally constitutive of it, universal-singular, infinity-finitude, eternal-temporal and need-freedom, antinomies that must be present in a balanced manner in the existing empirical and the self must be aware of them so that the Being itself emerges, otherwise the existing empirical and the self are lost in one of the poles of these relationships. Certainly, for example, Being itself "Cannot dissolve into something of a universal type, without losing its existence; but as long as it is merely singular it is not Being itself. To advent to Being itself means that the universal becomes singular and none is set aside" (Jaspers, 1960: p. 540). In this dialectic, there are degrees of consciousness that tend towards the individual, the individual factual existence, the individualistic conscious individual existence and the individualistic doctrine; as well as degrees of consciousness that tend towards the universal, existence of factual mass, universal conscious humanity and universalist doctrine. In the first degree, both the individual and the mass are immediately aware of themselves in an naive mode that allows perceptual objectification without further elaboration; in the second degree, there is a tendency to the dissolution of the objective by the 
conscious individualist consciousness and of the subjectivity on the part of the conscious universal humanity, and in the third degree, the unity of subject and object is harmoniously sought in concepts such as the personality that integrates, in the individual, the social factors or the absolute spirit that integrates the individual in the universal as a differentiated universal (Jaspers, 1960: p. 539). But this gradation must not lose sight of the fact that it is nothing more than a paraphrase of a process of getting into Being itself, infinite and therefore not objec-

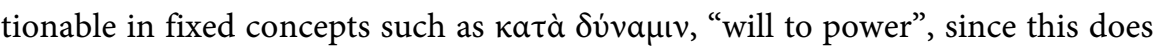
not really exist, but rather it must originate each time through self-awareness of the concrete synthesis of structural antinomy existential, that is, through the synthesis of the universal-singular, finitude-infinity, temporal-eternal and freedom-need.

This universal-singular dialectic as an example of the existential structural antinomies, is applied to the other existential antinomic relations as conditions of the becoming of the existing empirical in being itself, where the essential or the distinctive form that every antinomic relation must acquire in order for the Being itself to emerge is that the human being must "Be aware of the essence of this synthesis (...) the relationship must behave with itself; then it is the Being itself. Since man is a synthesis, his existence ceases, his self, when he loses a part of the synthesis" (Jaspers, 1960: p. 541). In effect, the finite without the infinite would determine a self without transcendence and therefore limited to a mere unconscious reflection of the existing empirical, on the contrary, a self with only infinity implies an unrealizable abstraction. The same with respect to the temporal and timeless, in the first case the self-stiffens determined by an improper time, in the second case it becomes ethereal. Regarding freedom and necessity, on one hand, the self passes into debauchery and on the other, the being there floods with its empirical needs without allowing the ego to develop elaborate intellections.

Being itself is the final cause of the following causal structure. The will, as an efficient cause, and expression of freedom (Jaspers, 1958b: p. 5), generates, by the efficient medium of reflection, self-consciousness, as a formal cause, in the existing empirical, as a material cause, generating the whole or the substance that is essentially Being itself, in such a way that "The more [self] consciousness, the more Being itself $(\ldots)$ the more will, the more Being itself. A man who has no will is not Being itself; but the more will he has, the more self-consciousness he has too" (Jaspers 1960, p. 541). In this way, it is the will that allows, as we will see later the leap from the limit situations and specifically from the limit situation of temporality, which in Heidegger (2015: p. 295), is conceived as the anguished call of the consciousness.

In relation to reflection, In common sense (Geertz, 1994: p. 107), reflection is thought as the reflection of a previously established internal reality, but the self is not a mere passive reflection of the being there, "but action, the process that Kierkegaard calls interiority" (Jaspers, 1960: p. 541). Whereupon, the interiority fuses Being itself with the will through reflection. It begins with reflection with the act of separation in which the self fixes its attention on their being there, and 
later on the relation of itself whit their being there, as something essentially different from the objective world, emerging as Being itself. Certainly, "in self-reflection [it] gets the 'awareness' of Being itself by which the infinite abstraction of everything external and this, Being itself is what drives forward in the whole process, by which a Being itself infinitely accepts his real itself with its difficulties and advantages" (Jaspers, 1960: p. 541). So the reflection that mediates the will, is an action that generates interiority and not only reflects it.

It should be noted, that the Being itself is not identical to self-awareness, in fact different self-consciousness can occur as formal causes of the Being itself through the historical evolution of Being itself, in Jaspers words, "Through Being itself there is always a self-concrete consciousness, but it advents and is not rigid, while the Being itself lives in its own sense" (Jaspers, 1960: p. 541). The first self-consciousness is obtained from the influence of parents who transfer a way of thinking to the child in their development, then they become men receiving as a rule the self-awareness or way of thinking that the State grants them to self-objectify. And an accent falls on the Being itself when it receives God as the norm. According to Jaspers (1960: p. 542), the norm or code from which self-consciousness is obtained "Always constitutes what this is in relation to which it is Being itself... the more image of God, the more Being itself; more Being itself, so much more image of God". In fact, the oceanic feeling from which the image of God emerges as the surrounding (Jaspers, 2017: p. 29), is an inexhaustible treasure of meaning that allows the ascent and patentization of the Being itself.

But the above does not mean that the form of self-consciousness obtained is a premade form for all the same, on the contrary, "The process of Being itself always clings to the living self-consciousness, which is so concrete that no writer, not even the one with the richest vocabulary or the one with the greatest power of exposure has ever been able to grasp a single self-consciousness of this type, while each singular man has it" (Jaspers, 1960: p. 542). Indeed, the fundamental thing is that although the Being itself is configured from the self-consciousness lent from social entities, in each existing empiricist it is substantiated differently depending on its singular historicity, which activates the universal-singular, temporal-eternal antinomies, in the way universal-social institutions, singular-existing empirical and temporary-existing empirical, eternal-social institutions.

In this advent of Being itself, the human being can choose the manifestation or the reserve as he actively develops the public exterior aspect of Being itself or his interiority. Just as in the manifestation there is the possibility of freedom of expression or loss of the Being itself in the mass if there is not existential communication (Jaspers, 1958a: p. 451), in the reserve, if this is not noble, being the product of shelter in a great idea, the possibility of self-confinement is given as slavery (Jaspers, 1960: pp. 542-543). Two vectors of the development of the self that refer to extroversion and introversion, and which in turn place another 
structural antinomy to be taken into account, internal-external.

On the other hand, the concept of Being itself is shown through layers of the ego, each of which captures an aspect of Being itself but in turn veil it in its intend of showing Being itself as it is. Thus, according to Jaspers (1958a: pp. 424-429), we cover ourselves and show ourselves through certain layers of the ego, these are, the body self, the role self, the production self and the past self. The body self, coincident with the being there, allows the self to show Being itself in its most basic being, and gives it substantiality in the world, but hides the self to the extent that this is not only body, but a self-conscious body conscious of its self-awareness. The self-role is an important form of manifestation of the self, in that at all times we are being part of a social structure and therefore fulfilling a certain type of social role, however, the self tends to be determined by the role it fulfills losing substantiality by forgetting the body and being determined by the form that is imposed from the bureaucratic siting structure. The production self considers that what one does is what it is, which is correct when the product coincides with the production, as evidenced when our work is to think and is done with intelligible matter, but in the vast majority of situations the production does not coincide with what has been produced, so the product of a good job can be negative or vice versa, hence, the product often conceals or contradicts the production. Finally, the past self, from which the present tends to be determined based on what has already been, which to some extent is correct, but when this aspect of the self is forced, it is held by elements of the past that instead of components, are presented as determinants of the present and even of a future destiny. Consequently, these layers of the ego must fall to make way for the resolute self that is the Being itself (Jaspers, 1958a: p. 40). The situations that make possible the fall of the layers of the ego and the emergence of Being itself as a resolution by the will that wants itself, are called limit situations.

\subsection{Limit Situation}

Jaspers' definition of the concept of situation, derives from a plastic perspective as the arrangement of things in a topographic spatial order, from this, comes to its own sense of the concept of situation as "a reality for a subject interested in it as an empirical being (...) the situation is not only a natural reality but rather a reality referred to a sense, which is neither physical nor psychic, but both at the same time as a concrete reality that for my empirical existence means advantage or harm, opportunity or impediment" (Jaspers, 1958b: p. 65). In the opened world by this definition, they make sense to the self in asymmetric arrangements, other subjects and their interests, objects and their vectors of movement and rest, as co-emerging entities from the circumvolant (Jaspers, 2017: p. 29), which as nothing in its symmetrical withdrawal (Heidegger, 2001: p. 101) is a condition of the emergence of each internally differentiated boundary situation. Certainly, we are in situations and these emerge from the structure absent from nothing, which as a background allows the configuration of the situation, a 
background that we don't perceive as such because we cannot perceive it empirically while immersed in a situation.

Situations are approached from the different sciences, for example, from the biological sciences, the biochemical dynamics of the entities will be studied, from the economy the situations will be studied as a product of supply and demand, from sociology as a product of social relations of power, from the arts as an aesthetic totality, from history for its uniqueness as an unrepeatable event or as a repetition structure, among other sciences. Actually, since Jaspers (1958b: p. 65), situations can be presented as typical generals or unique historically determined, the former are a generalization of the peculiar situations of everyday life, the latter are retrospectively intelligible from the determination of a unique fact generating historical qualitative changes. The first ones are studied in their quantitative accumulation with other previous and later situations, the second ones are studied in their qualitative substitution thought as a whole.

Regarding situations, it is always in perspective, which implies that it is not possible to be immersed in a situation, to fully grasp it, but strokes and backsides of situations are always captured depending on the physical and intellectual place from which each situation is conceptualized. On the other hand, an external viewer or oneself in retrospect can subsequently capture the situation in its generality, although always as a stylized representation of it, since each situation is a singular event.

Situations change, "While they change, there comes a time when they no longer exist" (Jaspers, 1958b: p. 66). It is evident that everyday life is composed of several situations and that precisely, every day is divided not only in hours but, firstly by situations in which we find ourselves, and how we pass from one situation to another or as the situation in which we are changes. But once they change, they are lived as given, as if their essence, that is, their distinctive form, was given a priori and per se. Although there is always the possibility of being able to modify them, producing new situations through actions regarding the purpose, we do not act directly in situations, but we create the situation as a horizon from which each action with related arrangements acquires meaning (Jaspers, 1958b: p. 66).

The situations are connected, being born from each other. Its connection can be given by all or some of the elements that make up each situation, as in everyday life, when one thing leads to another, or one thing is divided into many things or many things become one. The existing empirical is subject to connections of situations, whose laws can be known through science, but in a historical or changing way, since the same knowledge of the laws changes the laws, changing the situation. What follows is that situations do not change per se, but change with the behavior of the subjects involved in the application of the laws of behavior of the entities, so that individual performance changes direction if the context of performance changes.

Considering the previous, we can affirm that the existing empirical is a be- 
ing-in-situation, thereupon you can never leave a situation without immediately entering another, you can change the situation in which you are, but not the fact that you are in a situation, in consequence that "my action is presented to me in its consequences, in turn, as a situation created by me that already has been given" (Jaspers, 1958b: p. 66). I am in the track treadmill and after forty minutes of jogging I get tired and leave it to have dinner, immediately after, I entered in the social media, in which each one can be thought of as an avatar in situation that projects an aspect of the Being itself, then, being on the same Mac, I change my focus from the social networks in which I participate, Facebook, Instagram, Academy, among others, to concentrate on the writing of this article putting me in a situation of an intertextual dialogue with the editor of the magazine to whom I will send the text once is finished. Then, I will probably watch a movie on Netflix, putting myself in a situation of critical dialogue with the actors and the director, waiting at all time for the response of my tutor professor from my doctorate to arrive with his evaluation of my thesis draft. In fact, we cannot stop being in a situation, furthermore, every day we find ourselves in more than one situation at a time.

However, there are situations that cannot be changed beyond their modification in the way they manifest, they are presented as definitive and are opaque to the eye, beyond which nothing can be seen anymore, and can only be clarified by themselves, not through other situations, they are absolute, not relative, these are called by Jaspers, limit situations, "situations such as those of which I am always in a situation, that I cannot live without struggle and without suffering, that I inevitably assume the guilt, that I have to die, are what I call limit situations" (Jaspers, 1958b: p. 66). Limit, according to the author expresses that "there is something else, but at the same time, this other thing does not exist for the consciousness in an empirical existence" (Jaspers, 1958b: p. 67). The limit is both objective and subjective, these situations touch us all regardless of their singular concretization in each one, they all match us, but not everyone faces them, most seek to avoid them, ignore them, for example, we want to know nothing related to death, we always seek to avoid it as theming, or regarding to suffering, against what we have the illusion that we can reach a state in which suffering does not occur in us, a state that is rather an entelechy than the reality of permanent suffering during life.

The first limit situation looms when the existing empirical as a possible existence is always in a certain finite historical situation. Being a son, being a father, belonging to a family, having a profession, having a job, being a resident of a city, being a citizen of a state, are historically determined situations in which the existing empirical as a possible existence is always in them. In this situation, there is the tension of deciding for oneself or accepting what has been given as if it had been wanted. What has been given are properly the traditions in which we are thrown, in fact, through the exercise of spontaneity (Sartre, 1966: p. 207) we cannot escape them but renew them based on our fundamental project for the 
future (Ibid., 1966: p. 591). Hence, with these situations, historical awareness is created throughout the appropriation of tradition. On the other hand, the particular limit situations, death, suffering, struggle, chance, guilt, "affect, as general, all in their 'historicity', specific in each case" (Jaspers, 1958b: p. 73). The above situations may vary more freely than the specific limit situations, which occurs to all of us equally in distinctive ways. From these, derives a perspective of empirical existence thought as a whole historically, from which the being in the world in general is problematized, which means an elevation "to the indeterminate and absolute historical, as it is felt in the limit situation universal of all empirical existence" (Jaspers, 1958b: p. 71). This last level, consequently, is the global historical situation in which we find each individual as part of the universal subject. There is nothing beyond it, because it determines us all, not as much as individuals but as parts or gears of a great machinery that is world history.

\subsection{Temporality}

Time is properly a limit situation, although not considered by Jaspers, it does comply with presenting itself against the existing empirical as an existential limit, mainly in its present form, from which the existing empirical responds with an improper presentist time of waiting and forgetting its most characteristic possibility (Heidegger, 2015: p. 358). This is because time is presented as a present time and as a being in front of objects that appear as presence (Heidegger, 2015: p. 357). Being there, through the call of the consciousness, who is a deafening anguish in the face of the most proper possibility, advents to Being itself by becoming a resolute precursor and timing the time from the future (Heidegger, 2015: p. 359), at the moment that opens the situation where the entities show themselves in sight as instruments according to its project to Being itself (Heidegger, 2015: p. 357).

For Jaspers (1960: pp. 153-154), time acquires the following senses:

1) Time is conceived as an empty space in a quantitative and objective way, the present is considered as a mere limit and a point that separates past from the future, is the objective time of physics, which serves as a representation of the time of our life and by which we measure our daily activity, is the time of the clock that organizes the modern world.

2) The psychological time, but formal in order to its quantitative relationship, from this time the objective time does not exist, but its subjective experience that objectively considered, has a certain duration characterized by before, during and after.

3) Time considered epistemologically from Kant as a form of subjective conception from which we project the objective, is the form of objective existence in our subject-object expression, in the words of Kant (2018, p. 82) "Time is nothing more than the form of the internal sense, that is to say, of intuiting ourselves and our inner state", a form that is projected on the meaning of phenomena as past, present and future. 
4) From Plato, time has been conceived as the moment when this is the whole of the paradox between rest and movement, as the step to be and yet not to be, the moment through oppositorum coincidence is in absolute contradiction with eternity and however, in direct relation to it, the moment is then what makes us present, the change between rest and movement, a change that is considered as time.

5) From Kierkegaard, the moment is thought as full content, it is the source of what is unique, of the leap of decision, this is also the conception of the moment from existence or itself considered by Jaspers, namely, "existential time, as manifestation of the true being, is at the same time, the absolutely inexorable time, and the transcendence of this time in eternity" (Jaspers, 1958b: p. 414), is the time that is reached in existence, because the self abstains from time as past, present and future considering it as an external unit to the time of the Being itself that is the time of the reflective attitude (Jaspers, 1960).

6) And the metaphysics of time that moves in images that cancel time in favor of the eternal, thought of as the full eternity, among these, is the notion of Aristotle, "Who argues that time is infinite because of its relationship with the movement" (Aristotle, 2019: p. 372). Time is then the measurement of a movement thought of as a variation, while the unit of measure is also a variation, so the time of a walk is usually measured by the variation of the units of measurement called hours, minutes and seconds, but it can also be measured by the regular variation of the strokes of arms that are made, considering each pendulum movement back and forth of an arm as a unit of measurement, with which we would have our own time to measure the time of the walk, for example, such a walk lasted a certain number of pendulum movements.

To these conceptions can be added the conception of Sartre, who affirms that there is no time for the empirical being, but only for the itself or to Being itself in our terms, namely, "What is called itself does not have temporality, precisely because it is in-itself and temporality is the unitary way of being of a being that is perpetually distant from itself to itself. To-itself, on the contrary, is temporality" (Sartre, 1966: p. 271), in fact, "There is no temporality except as an intra-structure of a being that has to be its being; that is, as an intra-structure to-itself" (Sartre, 1966: p. 193), which reinforces the conception of time as a subjective sense that is projected on the entities that appears in front of the Being itself, which informs us that improper time is precisely forgetting our own time considering the time from the entities that are presented to us and in which, according to their disposition, we deal with. The own time on the other hand, would be to consider the time again as a projection that opens a sense on the entities instrumentalizing to the illuminated possibility with such projection.

Doubtlessly, as the last sense of semantization of temporality, we find Heidegger's definition, from which it is possible to understand time properly as a limit situation, namely, "The fundamental possibilities of the existence, ownership and impropriety of Dasein, are founded ontologically in different possible 
modes of temporality" (Heidegger, 2015: p. 304).

Certainly, time as temporality is the unitary phenomenon, "The future that is being been and presents" (Heidegger, 2015: p. 346), which is the ontological sense that unifies the attention, that is, the existential structure of the Dasein or Being itself, in such a way that "anticipating-itself is founded in the future. Being-already-in-itself accuses having-been. Being-in-the-middle ... is possible by the presentation" (Heidegger, 2015: p. 346), thus, care as an existential structure of Dasein is unified with the ontological path of temporeity, in such a way that the self has as a structure, the precursory preposition of itself in anguish disposition to return to being what has already been, being already in the world among the intramundane entities. Recall that for Aristotle (2019: p. 197) the being, that is, the subject of ontology, has "Meanings as categories there are (...) some are essences, others are qualitative, others designate the quantity, others the relationship, others the action or the passion, others the place, others the time: the being is taken in the same sense as each one of these modes". In this timing of the existential structure of Dasein or for itself or Being itself, the meaning unfolds from the projection of the future, in the words of the author, "Existentiality. The primary meaning of this is the future" (Heidegger, 2015: p. 328). In terms of Sartre (1966: p. 200), the above is seen as a display of the past in itself and the future for itself with emphasis on the present as not being, which puts in perspective the emphasis on the future, but overall, it reinforces the idea of time as an internal to the Being itself, born in Kant and with echoes in Heidegger and Sartre, and from which it can be thought of as proper time or improper time.

However, we are usually falling in the one, where we do not project a decisive precursor attitude, but we are waiting for the fearful and forgetful unresolved resolution of the most proper possibility, moved by talk, ambiguity and greed, technically, we move with improper time (Heidegger, 2015: p. 356), or as a merely empirical existing, but also as possible existing or Being itself. It must be pointed out, that as well as the concepts for itself and Dasein, the existence is considered a synonymous of Being itself, with an emphasis placed by that concept on the unitary relationship of Being itself with its world, in other terms, defined from an external other, while that Being itself in its most proper sense has a self-understanding emphasis, or a definition from within the dialogic relationship (Shotter, 2001: p. 57), mutatis mutandi, not in the cognitive sense but in the sense of self appropriation of the possibilities of my being there.

\subsection{Empirical Existence, Existence (Being Itself) and Limit Situations}

Understanding time as a limit situation, allows the empirical existing to exit from its fall into the halfway point of one, making the leap into existence or being itself through the exercise of an instantaneous precursor subjective attitude or proper time. But, what is existence?

The empirical existence or being there, is not the existence, "But man is, in empirical existence, possible existence. That one, the empirical one, is there or 
not; but existence, by the fact of being possible, advances towards its being. Or, on the contrary, it moves away from it, towards nothingness, by virtue of choice and decision" (Jaspers, 1958a: p. 392). Empirical existence has a narrower or wider being in the world, but existence or Being itself differs in the world, essentially because of its freedom, translated into decisive unconditional acts (Jaspers, 1958b: p. 376), in spontaneity, in the decisive precursor action, or as Martin-Santos (1964: p. 45) elegantly defines, "We will call, then, freedom to the psychic indeterminacy capable of being the origin of the meaning of life". Empirical existence lives and dies, but existence does not know death, but rather moments of "Ascent, fall and descent" (Jaspers, 1958a: p. 392). Empirical existence is closed on itself and determined by chronometric time, but Being itself or existence, as we have already seen, is in time, more than time, tends to the possibility of always being infinitely open. In other words, "The realization of the empirical existence is to be in the world. On the other hand, the possible existence is in the world as in the field in which it manifests" (Jaspers, 1958a: p. 393).

Only being itself exists, the existing empirical, the attitude in which we find ourselves in everyday life does not exist, but is immersed in the world. Though it can oppose the world and its own being there, and with this we move on to an internal definition, in that way "In a surprising independence, although empty, I also oppose my own empirical existence as an alien empirical existence (...) and I enter the world from it, to orient myself in my situations, not only as a simple living for my particular purposes, but as myself for my knowledge of everything and of the totality that, as knowing, is enough and satisfies it" (Jaspers, 1958b: p. 68). This dialectic in which I become existence or Being itself, then starts from a first leap from my factual existence not questioned, then a second leap of opposition between myself and my being there, and a third leap in which I return on my being there for itself, and for others. But these leaps are conditioned, precisely by situations and limit situations.

In fact, this facticity, the opposition and return with respect to the world and of the being there by which it advents to Being itself, is translated into a series of leaps, the first regarding everyday situations leads to thinking about images of the world or a knowledge of the world, the second, regarding limit situations and opposition to these, to think as a clarification of the existence or in the understanding of one's own possibilities, and the third, to philosophical life, to think that one thinks of oneself the same, or in other words, Being itself inserted into existence (Jaspers, 1958b: p. 71).

It advents to Being itself in limit situations. The limit situations do not exist for the consciousness in general, this eludes them, ignores and forgets, because they cannot see them as means for ends, but for their condition as objectives, they are there as limits of the consciousness according to ends, so "The limit situation belongs to 'existence' as situations to the always immanent consciousness" (Jaspers, 1958b: p. 67). It follows that limit situations are only addressed by Being itself and not by the existing empirical, since, as we know, it requires the will, reflection and self-awareness that do not reflect, but generate the interiority 
and the exteriority in which Being itself can emerge, either as a will to power, a will to pleasure or a will to make sense among other definitions to the sense of Being itself. In other words, in the limit situation... "a personal solution is necessary to accustom which implies change or development [the limit situation is a] super-individual challenges intrinsic to existence, thus unavoidable, and requiring a personal response which engenders maturation" (Mundt, 2014: pp. 169-170), of the unconditioned Being itself.

In fact, and this is the key, in the face of limit situations we do not react intelligently, through plans and calculations, as is done with immanent situations, but rather in a completely different way, through the will, "Becoming the possible existence that exists in us; We become ourselves entering limit situations with our eyes wide open (...) as realities can only be felt by existence. Experiencing the limit situations and existence are the same thing" (Jaspers, 1958b: p. 67). Certainly, according to Jaspers (1958b: p. 67) "While in empirical existence the question of being in the limit situations is strange, Being itself can be realized by the virtue of a leap: knowing that otherwise does nothing more than acknowledge the limit situations, it gives itself a unique, historical, irreplaceable plenitude" (Jaspers, 1958b: p. 67).

Therefore, there is a duplicity of being in the world, "As an empirical existence I am in situations; as a possible 'existence' in the empirical existence, I am in limit situations (...) after the leap is made, I am faced with an irreducible duplicity: not being merely in the world, and yet not existing more than while I manifest myself in it" (Jaspers, 1958b: p. 72).

Thence, we can conclude that time as a limit situation, because it is an incescapable situation, that generates the division between an empirical existing characterized by an improper time that is, being faint-heartedly waiting, determined by the present and by the presentation of the entities that generate an occupation situation. With the power of will, through the reflection, giving itself a self-consciousness, the possible existing can clarify its existence and appropriate the most proper possibilities of its being there, with a decisive precursor attitude that opens up such possibilities depending on the future, instrumentalizing the entities at hand and in sight based on a fundamental project, managing to advent to Being itself.

\section{Final Comments}

First, the concept of Being itself was defined, then the concept of the limit situation, and the concept of temporality. Finally, we related temporality, mainly from Heidegger, as a limit situation, which Jaspers had not considered as such, from which emerges Being itself.

Definitely, Being itself as existence and synthesis of antinomic structures becomes such by entering into limit situations, among which, temporality can be understood as one of them. In fact, being as mere being there or existing empirical, the self is immersed in the presentist boundary situation that elides the past 
and the future and considers the objects as present in sight in an attitude of waiting delivered to hearsay, ambiguity and greed for the new. Taking the leap into existence or for itself or Being itself, through a decisive precursor attitude and spontaneous unconditioned actions, the self is patented as existence, managing to go beyond time, exercising its own time, on the rise, displaying senses that are principles of life and getting patented in its historical being.

\section{Conflicts of Interest}

The authors declare no conflicts of interest regarding the publication of this paper.

\section{References}

Aristotle (2019). Metaphysics. España: Biblok Book Export.

Campos, H. (2017). Interpretación ontoepistemológica de Jaspers y Heidegger desde Holzapfel. Cinta moebio, 58, 74-88. https://doi.org/10.4067/S0717-554X2017000100074

Geertz, C. (1994). Local Knowledge Essays on the Interpretation of Cultures. Barcelona: Paidós Ibérica.

Heidegger, M. (2000). The Fundamental Problems of Phenomenology. Madrid: Trotta Editorial.

Heidegger, M. (2001). Milestones. Madrid: Alianza Editorial.

Heidegger, M. (2004). The Cuestion for the Truth. Madrid: Alianza Editorial.

Heidegger, M. (2015). Being and Time. Santiago: Editorial Universitaria.

Holzapfel, C. (2001). Absolute Conscience and Action in Jaspers. Philosophica, 24, 79-115. https://studylib.es/doc/284001/-conciencia-absoluta--y-acci\%C3\%B3n-en-jaspers

Holzapfel, C. (2014). Human Being (Anthropological Mapping). Santiago: Cinta de Moebio Ediciones.

Holzapfel, C. (2015). The World Man Link. Philosophical-Existential Exploration in Jaspers Perspective. Santiago: Cinta de Moebio Ediciones.

Jaspers, K. (1958a). Philosophy I. Madrid: Ediciones Revista de Occidente.

Jaspers, K. (1958b). Philosophy II. Madrid: Ediciones Revista de Occidente.

Jaspers, K. (1960). Psychology of World Conceptions. Madrid: Editorial Gredos.

Jaspers, K. (2017). The Philosophy. From the Point of View of Existence. México: Fondo de Cultura Económica.

Kant, I. (2018). Critique of Pure Reason. México D.F.: Fondo de Cultura Económica.

Martin-Santos, L. (1964). Freedom, Temporality and Transfer in Existential Psychoanalysis. Barcelona: Editorial Seix Barral.

McMillan, J. (2002). Jaspers and Defining Phenomenology. Philosophy, Psychiatry \& Psychology, 9, 91-92. https://doi.org/10.1353/ppp.2003.0011

Mundt, C. (2014). Jaspers Concept of "Limit Situation": Extensions and Therapeutic Applications. In T. Fuchs, T. Breyer, \& C. Mundt (Eds.), Karl Jaspers' Philosophy and Psychopathology (pp. 169-178). New York, Heidelberg, Dordrecht and London: Springer. https://doi.org/10.1007/978-1-4614-8878-1 11

Sartre, J.-P. (1966). Being and Nothingness. Buenos Aires: Editorial Losada.

Scheller, M. (1938). The Place of the Man in the Cosmos. Buenos Aires: Editorial Losada. 
Shotter, J. (2001). Conversational Realities the Construction of Life through Language. Argentina: Amorrortu Editores.

Van Manen, M. (2014). Phenomenology of Practice: Meaning-Giving Methods in Phenomenological Research and Writing. Walnut Creek, CA: Left Coast Press.

Wotjak, G. (1979). Research on the Structure of Meaning. Madrid: Editorial Gredos. 